\title{
AIDS Public Service Announcements: A Paradigm for Behavioral Science
}

\author{
Sandra L. Calvert \\ Georgetown University \\ RodNEY R. Cocking \\ The National Institute of Mental Health \\ Milena SMRCeK \\ Georgetown University
}

\begin{abstract}
A cognitive-behavioral model is applied to televised public service announcements as a paradigm for applied developmental psychologists to conceptualize and disseminate findings. Schematic processes are examined in relation to viewers' attenfion, retention, and motivation to change altitudes and behoviors after viewing public service announcements. Content and format changes are discussed as ways to increase effectiveness of social information processing models of behavioral change.
\end{abstract}

"This is drugs," the announcer says as butter burns in the frying pan. A broken egg drops into the frying pan and as the egg sizzles, the announcer continues, "This is your brain on drugs-Any questions?"

In the following position paper, public service announcements are examined as both a research paradigm for applied developmental psychology and as a model for translating research into practice. Paradigm in this context is defined as a "precise description of relationships among variables" (Thomas, 1985, p. 13). We utilize public service announcements as an example of how developmental processes from a variety of areas of behavioral science interrelate and influence multiply determined behaviors.

Public service announcements, as brief messages that are designed to educate and to alter people's attitudes and behaviors about serious social issues, reach millions of television viewers daily. Although viewers watch television primarily to be entertained, media such as radio and television are also primary sources of information. The question is, To what extent is the information effectively transmitted? As we will point out in the case of an important worldwide problem of

The authors thank Mr. Hans Wolf, Mrs. Hannelore Frechen, Mr. Toeppich, Mrs. Edith Haider, and Ms. Margie Fox for providing information about AIDS and the educational campaigns designed to fight the spread of the disease.

Correspondence and requests for reprints should be sent to Sandra L. Calvert, Department of Psychology, Georgetown University, 37th and O. Streets NW, Washington, DC 20057. 
AIDS, AIDS public service announcements are relatively devoid of content. This finding was consistent across countries in a multinational study. In addressing how behavioral science can be put into practice and how social problems can be conceptualized as issues in basic science, we will discuss the behavioral issues, applied issues, and implementation strategies as a set of interrelated concerns for paradigms in behavioral science.

\section{PUBLIC SERVICE ANNOUNCEMENTS}

Health-related issues are an important, but underused, area of television transmission (Gerbner, Morgan, \& Signorelli, 1982). Public service announcements tackle varying health-related social issues like drug abuse, AIDS, smoking tobacco, and wearing seat belts in televised spots that range from 10 to $60 \mathrm{~s}$. The intent of public service announcements is to make viewers aware of problems, to convey information to the public, and to provide the viewer with additional resources for information as needed. Television is an effective way to deliver them.

The format of public service announcements is similar to commercials in that both are brief, transmit a message quickly, appeal to viewer emotions, and attempt to influence viewers' attitudes and behaviors. Because of this format, public service announcements are uniquely suited to deliver information to the public because they are quick and to the point. Only a short attention span is required to view the entire message, and these messages can be presented in a very visible format.

The more limited budgets of public service announcements provide both benefits and liabilities. On the one hand, the limited cost of public service announcements and the free air time on television allow behavioral scientists to use them to disseminate findings. On the other hand, however, the limited budgets may prevent public service announcements from being as effective as are commercials. In commercial selling, attention-getting production features like action and sound effects are emphasized to make certain content salient (Huston $\&$ Wright, 1983), and hence the product becomes more desirable to viewers. These productions can be very expensive, and thus, quality and effectiveness often vary according to budgets. Not surprisingly, the budgets of commercials and public service announcements are very different. To see the magnitude of the difference, one need only compare the one million dollar Michael Jackson Pepsi commercial to the approximately $\$ 20,000$ production cost of the egg public service announcement about drug abuse we quoted in the beginning.

\section{IMPACT OF PUBLIC SERVICE ANNOUNCEMENTS}

Behavioral change that is brought about by public service announcements is related to four classes of variables: attention, comprehension, motivation, and 
attitudes. In the following section, the conceptual and empirical links among these variables are examined. Viewers' schemas about the personal relevance of information are used as an organizing construct.

\section{Attentional Effects}

In the initial phases of information processing, the viewer decides if the message is attention worthy or not, a judgment which is influenced by a viewer's expectations that the forms and content are both interesting and comprehensible (Wright \& Huston, 1983). Certain production forms are important for directing children's attention to content, whereas other factors are more important for getting adults' attention. For example, animation and peculiar voices activate a schema in young children that says "for me" and a schema in adults that says "not for me," but the opposite is true for adult male narration (Anderson \& Lorch, 1983). Formal features can serve as markers that guide the viewers' attention to content that is targeted for them (Calvert, Huston, Watkins, \& Wright, 1982; Lorch, Anderson, \& Levin, 1979).

Comprehensibility also affects viewers' attentional decisions about whether the message is for them or not. Viewers attend when the message is understandable, and they stop attending when the message is either too difficult (Anderson \& Lorch, 1983) or too easy to comprehend (Huston \& Wright, 1983). One challenge of public service announcements is to present a message clearly in a very short period of time. For this reason, the message must focus on only one or two points or viewers may miss the message entirely.

\section{Comprehension Effects}

Comprehension of television content is an active process guided by schematic processing, learned expectations that guide perception, memory, and inference (Calvert \& Huston, 1987). One of the simplest schemas that children develop divides the world into two categories: (a) content that is "for me," and (b) content that is "not for me" (Martin \& Halverson, 1981). Content that is "for me" receives more attention, is elaborated upon, and is remembered better than content that is "not for me." We believe that this type of schema is instrumental in making a public service announcement effective. So how does a viewer decide that a message is "for me"?

Personal experiences influence viewers' decisions about the relevance of televised messages. Viewers differ in the underlying knowledge bases that they have encoded about a topic, and this prior knowledge affects what they learn from a viewing situation (Calvert \& Huston, 1987). Age differences exist between adults and children in their knowledge about the sexual transmission of AIDS, but adults also differ from one another based on personal experiences. Personal experiences also mediate these knowledge bases between age cohorts. For example, children with AIDS probably have more sophisticated knowledge of medical equipment and procedures than do healthy adults. 
Television content is presented in both a visual and verbal format that parallels the iconic and symbolic representational systems that viewers bring to the viewing situation (Calvert et al., 1982). These television formats also affect viewer comprehension. Young children need concrete dialogue (Anderson, Lorch, Field, \& Sanders, 1981) and visual emphasis (Calvert, Huston, \& Wright, 1987) to get a message, whereas adults understand abstract, verbal messages which rely less on visual emphasis (Hayes \& Birnbaum, 1980). However, the possibility that older viewers may need concrete depictions when they have little prior knowledge of a topic has not been considered.

\section{Motivational Effects}

Getting the message across does not mean that behavior will automatically change. Viewers must be motivated to change behavior, a process that is linked to beliefs about the personal relevance of an issue. If viewers deny the relevance of the message for them, there will not be a link between personal behaviors and the message. Viewers must see some potential benefits in order to make changes (Bandura, 1986).

Televised models that are admired by viewers or that are similar to viewers can motivate behavioral change (Bandura, 1986). For example, when a popular young television star tells viewers to say no to drugs, many viewers will try to act accordingly. Perceived similarity is targeted in an antidrug public service announcement when a tearful adolescent says that she never thought that she would become addicted to crack.

These examples of "narrowcasting" may be more effective than transmitting general messages to the viewing audience because particular groups can be targeted for the specific behaviors that put them at risk. The problem with narrowcasting is that a problem may become too narrowly defined, and other target groups such as upper-middle-class college students who are not generally associated with either the behaviors or social problems in question may develop a schema that says "not for me." Reaching these groups may then become increasingly difficult.

\section{Attitudinal Change}

The attitudes or opinions that people hold about varying topics or groups of people are affected by television portrayals (Dorr, 1986). Stereotyped television presentations about men and women, for example, can activate and reinforce viewers' schemas about these groups (Calvert \& Huston, 1987).

Scare tactics are one type of emotional appeal used in public service announcements to affect attitudes. The antidrug campaign about frying your brains on drugs, for instance, delivers little factual information to viewers. Instead, the intent is to raise the viewers' awareness to a level of fear that will frighten them into feeling that drugs cause harm. 


\section{Summary: Behavioral Change and Production Effects}

Health-related public service announcements which are of viewer self-interest tend to be most effective (Paletz, Pearson, \& Willis, 1977). This suggests that the viewer must categorically define the message in the initial stages as relevant-or in other words, as "for me."

Once the viewer defines the problem as personally relevant, then the mechanisms for behavioral change require clear information about what one should do and support systems to help the viewer make those changes. For example, public service announcements tell the viewer to wear a seat belt or to stop smoking. Public service announcements about AIDS have been far less explicit about the use of condoms because of the sensitive nature of such public discussion (Watkins, 1988).

Although antismoking public service announcements have reduced the number of cigarette smokers in the U.S. (Weis \& Burke, 1986), steadfast smokers continued to smoke (Paletz et al., 1977). Putting on a seat belt is relatively easy to do, but addictive behaviors like smoking and drug use are much more difficult to change. Antismoking campaigns have demonstrated that support groups are instrumental in helping people quit smoking. Those who demonstrate addictive behaviors like smoking tobacco or using drugs, then, require both information about the problem and follow-up support in order to change their behaviors. Public service announcements can provide information about the problem and a preliminary support system like a telephone hot line for people to call for more assistance, but more elaborate support systems will probably be necessary.

In summary, personal experiences affect viewer decisions about content relevance, thereby affecting interactions among processes of attention, comprehension, and motivation. Prior knowledge about a topic affects the comprehensibility of the message, thereby influencing the viewers' decisions whether or not to attend to the public service announcement. If the message is delivered effectively, public service announcements have the potential of impacting the viewer at an attitudinal and behavioral level.

\section{Implications for Effective Public Service Announcements}

The paradigm put forth here for affecting behavioral change leads to implications for the content of public service announcements. First, producers and behavioral scientists must clearly identify the intended audience in the context of the public service announcement in order to elicit attention and interest to the message from the targeted viewers. Second, content and forms must be comprehensible and to the point so that the message can be understood. Third, messages about other groups should reduce any ambiguity about the targeted behavior in order to prevent discrimination towards those who have the problem in question. Fourth, some form of follow-up treatment and intervention should be available for those who have the targeted behavioral problem. 


\section{AIDS PUBLIC SERVICE ANNOUNCEMENTS: A CASE IN POINT}

To illustrate these points; we will describe a comparative study of AIDS public service announcements from three countries: the U.S., Germany, and Austria. With the deadly epidemic of AIDS sweeping the world and with no cure in sight, many countries have turned to televised public service announcements in an attempt to alter people's behaviors. We wondered if the varying public information strategies of these countries would be similar or different, and if the U.S. public information campaign would change as we gained more knowledge about AIDS. The first issue considered involves what we know about effective behavior change that is relevant to AIDS.

AIDS is transmitted primarily in three ways: (a) during sexual intercourse with an infected partner, (b) through contact with infected blood, and (c) from mother to child prenatally or by breast feeding (Batchelor, 1988). No one has contracted the disease through casual contact in social settings like schools, businesses, and public rest rooms (Batchelor, 1988).

The early targets for behavioral change began with the most affected groups: HIV+ homosexual men and intravenous drug users. Studies have shown that some groups of homosexual men have changed their practices to prevent the spread of the disease, but comparable changes have not been seen among intravenous drug users (Martin, 1986). These group differences may well reflect differential access to information, differential attitudes toward the message, differential comprehension of the messages, and differential access to the means for prevention.

\section{Content Analysis of AIDS Public Service Announcements}

Because most Americans get information about AIDS from news media (Ogilvy \& Mather, 1988), television campaigns have been targeted as a means to educate the public both in the U.S. (Brooks-Gunn, Boyer, \& Hein, 1988) and in Europe. For the comparative study, we obtained the written scripts for public service announcements produced in 1987 from the U.S., Germany, and Austria. The U.S. also provided the scripts from public service announcements produced in 1988. There were 10 German spots, 9 Austrian spots, and two sets of American spots ( 6 from the 1987 campaign, and 6 chosen randomly from a sample of 38 from the 1988 campaign). German was spoken in the German and Austrian public service announcements, and English was spoken in the American public service announcements.

The public service announcements from the U.S. (both samples), Germany, and Austria were compared by using a questionnaire that was created by 5 judges. Based on the verbal scripts and the literature on AIDS, categories were created which dovetailed with variables that were relevant for behavioral changes to occur. Attentional and motivational issues were addressed by rating who the target audience was. Content dimensions included the amount of medical information, information concerning transmission of the disease, and prevention in- 
formation. Attitudes were examined by rating the information that was presented to prevent unnecessary fear and discrimination and by rating the emotional tone used to deliver the message. Behavioral change issues were addressed by rating the provisions of additional information through resources like telephone hot lines. Finally, ratings about the perceived effectiveness of the public service announcement were obtained.

Four raters, who were bilingual in English and German, independently judged each script for the presence or absence of information in those categories. Three categories, including the intended audience, were dropped due to low reliability. The remaining questionnaire items and ratings are presented in Table 1 (p. 262).

\section{RESULTS}

\section{Cross-Cultural Comparison of AIDS Public Service Announcements}

The public service announcements of the U.S., Germany, and Austria were remarkably similar in terms of content, but primarily because all presented very little content. More specifically, medical information about the disease, how the disease is transmitted, and how to protect oneself from infection were infrequently presented by any of these three countries. Issues about the targeted audience could not even be evaluated because of low reliability on that category.

Cross-cultural differences were found, however, in information presented that may affect attitude formation. More specifically, the amount of information provided by different countries which may reduce both personal fears and discrimination towards AIDS patients varied, $\chi^{2}(2, N=25)=16.42, p<.001$. Germany and the U.S. provided more information to reduce viewers' fears about AIDS and to reduce discrimination against AIDS patients than did Austria. See Table 1.

There were also cultural differences in the follow-up services provided for groups who had received the message, a difference that may well affect actual behavioral changes made by viewers. Germany provided the most access to information resources like telephone hot lines followed by the U.S. and Austria, respectively, $\chi^{2}(2, N=25)=24.12, p<.001$. See Table 1 .

When we compared the 1987 and 1988 samples of public service announcements produced in the U.S., we found them to be very similar. The only change from 1987 to 1988 was that information which might reduce unnecessary fears about AIDS and information about potential discrimination against AIDS patients was totally eliminated, $\chi^{2}(1, N=12)=9.60, p<.01$. This finding suggests that the AIDS campaign in the U.S. was getting worse rather than better in terms of information that affects attitude formation. See Table 1.

\section{A PARADIGM FOR APPLIED DEVELOPMENTAL PSYCHOLOGY}

The purpose of this article is to provide applied developmental psychologists with a paradigm for conceptualizing research and research findings. Televised public service announcements, which are viewed by large audiences, can be an 
TABLE 1

Frequency of Information Presented About ADS for Germany (G), Austria (AU), and the United States (US1 $=1987$ and US2 = 1988); $A=$ Information Absent; P = Information Present

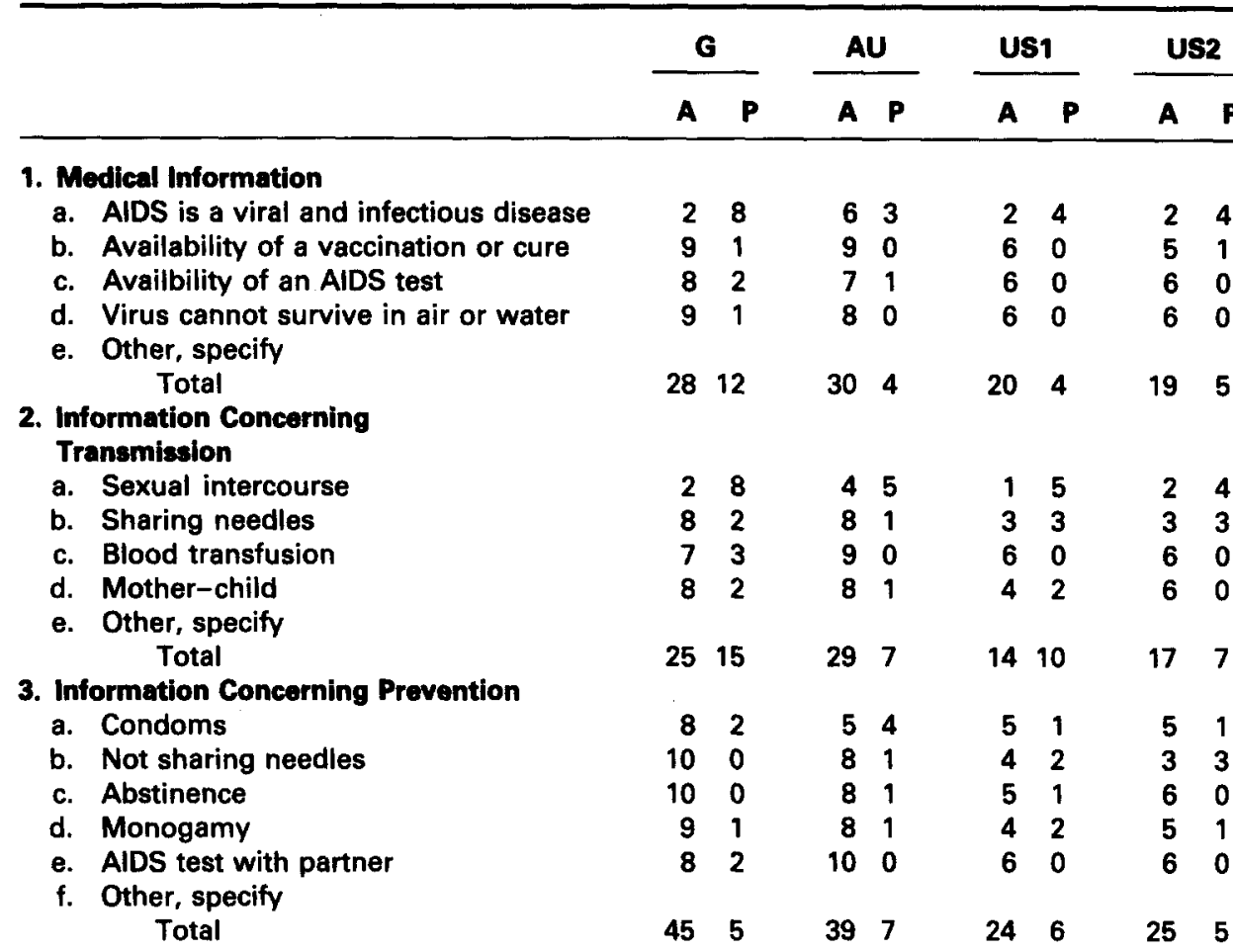

4. Information to Eliminate Unnecessary Fear or Discrimination
a. No danger of infection in social settings
b. No danger when working with colleagues
c. No danger when children play with each other

$\begin{array}{rrrrrrrr}4 & 6 & 9 & 0 & 4 & 2 & 6 & 0 \\ 6 & 4 & 9 & 0 & 4 & 2 & 6 & 0 \\ 6 & 4 & 8 & 1 & 4 & 2 & 6 & 0 \\ 7 & 3 & 9 & 0 & 4 & 2 & 6 & 0 \\ 23 & 17 a & 35 & 10 & 16 & 8 & 24 & 0^{*}\end{array}$

5. Additional Information (What kind of information?)
a. Address for more information (G only)
010
b. Hot line telephone number
010
90
24
06
c. Other, specify
$020^{\circ}$
$91 \mathrm{c}$
24
06

Note. For the cross-cultural comparison, categories with different letter superscripts are significantly different at $p<.05$ or greater. For the 1987-88 US comparison, an asterisk indicates a significant difference at $p<.01$. 
effective intervention mechanism for a variety of social issues that applied developmental psychologists study. At present, the war on drugs and the war on AIDS are areas to focus educational and prevention efforts. Television is a powerful vehicle for transmitting this information.

The cognitive-behavioral model focuses on viewer variables of attention, comprehension, and motivation to change attitudes and behaviors. Decisions about content relevance ("for me" or "not for me") raise issues of cognitive schemas and are the focal point for getting the message to the viewer and for suggesting processes of behavioral change. The content of televised public service announcements about AIDS was examined in relation to these viewer attributes.

The first problem was to define the target audience. In the international public service announcement study, we could not clearly identify any specific target audience, and therefore, the target audience probably did not connect the relevance of the message to itself. Public service announcements in Great Britain, for example, increased the public's understanding of AIDS, but gains in information did not affect behavior probably because viewers did not perceive themselves as an at-risk group (Wober, 1988). This implies that in addition to presenting a comprehensible message, public service announcements must clearly identify the target audience if viewers are to own problems and become motivated to change behaviors.

One clear challenge of an AIDS campaign is to get each viewer to define this epidemic and the public service announcements as "relevant to me." The early concentration of AIDS in HIV + homosexual men and intravenous drug users may have led to schemas in the U.S. that AIDS is a disease of gay men and intravenous drug users. Since AIDS is also spread through heterosexual intercourse, a new schema of potential danger emerged. More specifically, sexually active heterosexual groups, such as adolescents and college students, may have developed a schema that AIDS information is not personally relevant.

Narrowcasting to additional groups is one potential way to broaden the scope of the target audience. Although former U.S. Surgeon General Koop called for early education about AIDS to prevent the spread of the disease, public service announcements are not yet directed toward adolescents.

Production features were not formally analyzed in the AIDS public service announcements, but we did note that the American announcements relied on the "talking heads" approach. That is, actors speak to the audience in bits that contain few attention-getting electronic embellishments like action or sound effects. We could learn a great deal from advertisements in this area, for commercials are designed to enhance viewers' attention to, and their behaviors toward, a product. One way to improve public service announcements may be to use the same type of formal features that are found in commercials. Sound effects, for example, are a very cost effective form that can elicit attention from an inattentive audience (Calvert \& Gersh, 1987). 
Comprehensibility also affects viewers' attention (Anderson \& Lorch, 1983), but the contentless nature of many public service announcements means that there is very little information to comprehend. This finding raises an interesting question: Should public service announcements simply pique the publics' interest in an issue, or should they also inform? How much information can be delivered in 30 to $60 \mathrm{~s}$ without packing the information so densely that little is understood?

In a cross-cultural comparison of AIDS public service announcements from Canada, Denmark, Norway, Sweden, Great Britain, and the U.S., the announcements rated as most effective by at-risk groups were those which presented facts in a simple, frank manner (Baggaley, 1988). Several public service announcements which were rated as most effective were never broadcast because the messages were too direct (Baggaley, 1988). So while public service announcements can deliver comprehensible messages quickly, the AIDS public service announcements tend to be contentless probably because they deal with sensitive information. The failure of public service announcements to convey basic prevention information may limit their impact.

The power of television to shape preferences and attitudes toward commercial products is widely acknowledged (Atkin, 1982). Television also affects viewer schemas and attitudes toward other people (Calvert \& Huston, 1987). Data from public service announcements in Austria paid little attention to the publics' fears about AIDS, and public service announcements in the U.S. deleted this information in the 1988 sample. Although some viewers may not define themselves as at risk for AIDS, the disease has affected their attitudes about groups who do have the disease. Because homosexual men and intravenous drug users are social "out groups," unfavorable attitudes toward these groups is not uncommon. The additional fear of AIDS can led to increased discrimination and violence against these groups (Morin, 1988). Information about how AIDS is transmitted, however, can lead to a reduced fear about AIDS as well as increased empathy for AIDS patients (Royce, Dhooper, \& Hatch, 1987). Thus, public service announcements have the potential to decrease fears about how the AIDS virus is spread (Baum \& Nesselhof, 1988).

Getting the information across accurately is only the first step to behavioral change (Bandura, 1986). Viewers have to acknowledge personal relevance of the message, and then try to effect changes in their behaviors. Telephone hot lines were the method of choice for follow-up support service for those who have AIDS or who may be at risk for the virus. As any behavioral scientist who studies eating disorders and addictive behaviors can attest, changing behavior is difficult business. Logos like "Just say no" are catchy, but access to information is usually insufficient for behavioral change by intravenous drug users; users must also have a means to change behavior, such as drug treatment programs (Des Jarlais \& Friedman. 1988). The assessment here, then, is that telephone hot lines provide an initial means to help a person begin to change behavior, but other necessary resources should be provided once the phone contacts are made. 
Ultimately, the most important goal of public service announcements is to change life-threatening behaviors and to cultivate life-enhancing ones. This mission, after all, is the domain of applied developmental psychologists. Given the past success of public service announcements to reduce the number of smokers in American culture (Weis \& Burke, 1986), this approach can provide much needed information about how the public can protect themselves against AIDS or drugs or teenage pregnancy.

\section{CONCLUSIONS}

Questions that derive from applied problems have often defined research areas, but they can also drive research directions, as well. The use of public service announcements by applied developmental psychologists is a promising, but challenging, case in point. To meet time constraints of public service announcement air times, complex issues have to be addressed quickly and simply. Controversial issues must be addressed in sensitive, but informative, ways to meet the acceptability standards of viewing audiences. Controversial content can be provided through telephone hot lines, a commonly used international strategy. To address this kind of concern in science, applied developmental researchers who can synthesize information for relevant target groups need to be brought into research teams. Although the number of viewers who call the telephone hot lines will never approach the massive audience present when public service announcements are broadcast, public service announcements can stimulate target individuals to obtain follow-up information that may be too sensitive for community standards.

An eclectic approach which synthesizes varying theoretical frameworks such as information-processing, cognitive-behavioral, social-learning, socialcomparison, and social information-processing models should be tested in applied settings. One such setting is televised public service announcements where communication, symbolic encoding, attentional, attitudinal, and motivational constructs are all relevant to behavioral change and are tested in the ecologically valid contexts of viewers' homes.

\section{REFERENCES}

Anderson, D.R., \& Lorch, E.P. (1983). Looking at television: Action or reaction? In J. Bryant \& D.R. Anderson (Eds.), Children's understanding of television: Research on attention and comprehension (pp. 1-33). New York: Academic.

Anderson, D.R., Lorch, E.P., Field, D., \& Sanders, J. (1981). The effects of tv program comprehensibility on preschool children's visual attention to television. Child Development, 52, 151157.

Atkin, C. (1982). Television and consumer role socialization. In D. Pearl, L. Bouthilet, \& J. Lazar (Eds.), Television and behavior: Ten years of scientific progress and implications for the eighties: Vol. 2. Technical reviews (pp. 191-200). Washington, DC: U.S. Government Printing Office. 
Baggaley, J.P. (1988). Perceived effectiveness of international AIDS campaigns. Health Education Research, 3, 7-17.

Bandura, A. (1986). Social foundations of thought and action. Englewood Cliffs, NJ: Prentice-Hall.

Batchelor, W. (1988). AIDS 1988: The science and the limits of science. American Psychologist, 43, 853-858.

Baum, A., \& Nesselhof, S. (1988). Psychological research and the prevention, etiology, and treatment of AIDS. American Psychologist, 43, 892-898.

Brooks-Gunn, J., Boyer, C., \& Hein, K. (1988). Preventing HIV infection and AIDS in children and adolescents: Behavioral research and intervention strategies. American Psychologist, 43, 958-964.

Calvert, S.L., \& Gersh, T.L. (1987). The selective use of sound effects and visual inserts for children's television story comprehension. Journal of Applied Developmental Psychology, 8 , 363-375.

Calvert, S.L., \& Huston, A.C. (1987). Television and children's gender schemata. In L. Liben \& M. Signorella (Eds.), New directions in child development: Vol. 38. Children's gender schemata: Origins and implications (pp. 75-88). San Francisco: Jossey-Bass.

Calvert, S.L., Huston, A.C., Watkins, B.A., \& Wright, J.C. (1982). The relation between selective attention to television forms and children's comprehension of content. Child Development, $53,601-610$.

Calvert, S.L., Huston, A.C., \& Wright, J.C. (1987). Effects of televised preplay formats on children's attention and story comprehension. Journal of Applied Developmental Psychology, 8 , 329-342.

Des Jarlais, D., \& Friedman, S. (1988). The psychology of preventing AIDS among intravenous drug users: A social learning conceptualization. American Psychologist, 43, 865-870.

Dorr, A. (1986). Television and children: A special medium for a special audience. Beverly Hills, CA: Sage.

Gerbner, G., Morgan, M., \& Signorelli, N. (1982). Programming health portrayals in television. In D. Pearl, L. Bouthilet, \& J. Lazar (Eds.), Television and behavior: Ten years of scientific progress and implications for the eighties: Vol. 2. Technical reviews (pp. 291-307). Washington, DC: U.S. Government Printing Office.

Hayes, D., \& Birnbaum, D. (1980). Preschoolers' retention of televised events: Is a picture worth a thousand words? Developmental Psychology, 16, 410-416.

Huston, A.C., \& Wright, J.C. (1983). Children's processing of television: The informative functions of formal features. In J. Bryant \& D.R. Anderson (Eds.), Children's understanding of television: Research on attention and comprehension (pp. 35-68). New York: Academic.

Lorch, E.P., Anderson, D.R., \& Levin, S.R. (1979). The relationship of visual attention to children's comprehension of television. Child Development, 50, 722-727.

Martin, C.L., \& Halverson, C.F. (1981). A schematic processing model of sex-typing and stereotyping in children. Child Development, 52, 1119-1134.

Martin, J.L. (1986). AIDS risk reduction recommendations and sexual behavior patterns among gay men: A multifactorial categorical approach to assessing change. Health Education Quarterly, $13,347-358$.

Morin, S. (1988). AIDS: The challenge to psychology. American Psychologist, 43, 838-842.

Ogilvy \& Mather. (1988). The America responds to AIDS campaign highlights from year one. Washington, DC: Ogilvy \& Mather Public Affairs.

Paletz, D.L., Pearson, R.E., \& Willis, D.L. (1977). Politics in public service advertising on television. New York: Praeger.

Royce, D., Dhooper, S.S., \& Hatch, L.R. (1987). Undergraduate and graduate students' attitudes towards AIDS. Psychological Reports, 60, 1185-1186.

Thomas, R.M. (1985). Comparing theories of child development (2nd ed.). Belmont, CA: Wadsworth. 
Watkins, J. (1988). Responding to the HIV epidemic: A national strategy. American Psychologist, 43, 849-851.

Weis, W., \& Burke, C. (1986). Media content and tobacco advertising: An unhealthy addiction. Journal of Communication, 36, 59-69.

Wober, J.M. (1988). Informing the British public about AIDS. Health Education Research, 3, 19 24.

Wright, J.C., \& Huston, A.C. (1983). A matter of form: Potentials of television for young viewers. American Psychologist, 35, 835-843. 